\title{
Covid-19 in stock markets: a Complexity perspective
}

\section{Eder Johnson de Area Leão Pereira}

Programa de Modelagem Computacional, SENAI Cimatec, Av. Orlando Gomes 1845, 41.650-010, Salvador, BA, Brazil

Instituto Federal do Maranhão, Brazil

\section{Paulo Ferreira}

VALORIZA - Research Center for Endogenous Resource Valorization, Portalegre, Portugal Instituto Politécnico de Portalegre, Portalegre, Portugal

CEFAGE-UE, IIFA, Universidade de Évora, Largo dos Colegiais 2, 7000 Évora, Portugal

\author{
Hernane Barros de Borges Pereira \\ Programa de Modelagem Computacional, SENAI Cimatec, Av. Orlando Gomes 1845, 41.650-010, Salvador, BA, \\ Brazil
}

\begin{abstract}
This paper aims to analyze the effects of Covid-19 on financial markets from the perspective of Complexity. The Covid-19 pandemic has caused turmoil in financial markets and is already one of the most important financial crises in history, causing a fall in several stock markets as well as great volatility. Unlike past crises, which in most cases were caused either by problems of fiscal deficits or in the financial system, this crisis has its origin in an epidemic disease, which occurred in Wuhan, China, and quickly spread across the globe affecting transport networks, commerce and finance, and will affect the public debt of many countries. This is a systemic situation in which there is a need to consider several interconnected systems, financial instability and high financial risk, something that econophysics and some complexity theorists already do.
\end{abstract}


Therefore, this paper intends to show, theoretically, the systemic and complex character of the recent financial crisis caused by Covid-19.

Keywords: Complexity; Covid-19; Networks; Stock Markets; Power laws. 


\title{
Covid-19 in stock markets: a Complexity perspective
}

\begin{abstract}
This paper aims to analyze the effects of Covid-19 on financial markets from the perspective of Complexity. The Covid-19 pandemic has caused turmoil in financial markets and is already one of the most important financial crises in history, causing a fall in several stock markets as well as great volatility. Unlike past crises, which in most cases were caused either by problems of fiscal deficits or in the financial system, this crisis has its origin in an epidemic disease, which occurred in Wuhan, China, and quickly spread across the globe affecting transport networks, commerce and finance, and will affect the public debt of many countries. This is a systemic situation in which there is a need to consider several interconnected systems, financial instability and high financial risk, something that Econophysics and some complexity theorists already do. Therefore, this paper intends to show, theoretically, the systemic and complex character of the recent financial crisis caused by Covid-19.
\end{abstract}

Keywords: Complexity; Covid-19; Networks; Stock Markets; Power laws.

\section{INTRODUCTION}

The outbreak of the coronavirus 2 (SARS-CoV-2) respiratory syndrome has already 2435876 confirmed cases and has caused 167639 deaths worldwide until April 20, 2020, and numbers continue to grow (WHO, 2020). The first case of COVID-19 was registered in China in December 2019, and since then, the virus has spread quickly around the world (Wang et al., 2020). The World Health Organization (WHO) classified it as a pandemic on March 11, 2020. 
One of the measures to prevent transmission between individuals is physical social isolation (Henrique, 2020), meaning $1 / 3$ of the planet has to stay at home to decrease the probability of people being contaminated and affecting an entire global production chain (Dong et al. 2020). To avoid the damaging effects of the crisis, the governments of the United States, Eurozone and China have already spent more than 2.5 trillion dollars, showing that this is the biggest crisis since the subprime one, in terms of government spending for economic recovery, and one of the largest in history.

According to Wagner (2020), the crisis caused by Covid-19 is complex. Thus, a complex system approach is necessary to understand it. The use of complex systems to analyze finance appears in several studies, for example, Mantegna (1999), Bouchaud and Potters (2003), Chakrabarti et al. (2006), Farmer and Foley (2009), Farmer and Geanakoplos (2009), Kwapień and Drożdż (2012), Battiston et al. (2012a), Ferreira et al. (2016) or Sornette (2017), among many others. Two tools of complex systems have contributed to understanding financial instabilities: power laws and complex networks. They made it possible to expand two ideas: the first is that extreme events, like financial crises, are recurrent in the economy (and this can be studied by power laws); the second is that several systems, independently of being in finance, macroeconomics or microeconomics, are interconnected and subject to shocks.

Additionally, complexity makes it possible to analyze financial markets as being subject to abrupt changes when they reach a given threshold, that is, a point at which shocks can change the system's trajectory (Sornette, 2017). Furthermore, the hypothesis developed by Helbing (2013), that the increased connectivity of various systems such as the environment, public health, corruption, industry and the financial system, contributes to an increase in systemic risk, creating a situation of hyper-risk. 
Therefore, this paper intends to show that the complexity approach, used to analyze financial markets as an interconnected system and subject to great variations, is a theoretical option for understanding the financial crisis caused by Covid-19. The main ideas originating from this approach will be demonstrated, in particular the analysis of Econophysics and the use of power laws and complex networks. The goal is to show that the Covid-19 financial crisis can be characterized as a complex phenomenon.

\section{ECONOPHYSICS AND POWER LAWS}

Econophysics is a neologism used in the branch of Complex Systems from Physics seeking to make a complete survey of the statistical properties of financial markets, using the immense volume of available data and the methodologies of statistical physics (Mategna and Stanley, 1999). The term Econophysics was coined by Stanley et al. (1996) when they analysed the Dow Jones index and found that stock returns followed a power law distribution, contributing to the emergence of this new research field.

The idea that stock returns follow a power-law format is recurrent in Econophysics (see, for example, Stanley et al., 1996, Lux, 1996, Mantegna and Stanley, 1999 or Gabaix, 2009, among many others). One power-law can be defined as $y=$ $k^{\wedge} x \alpha$, where $k$ and $\alpha$ are constants, asymptotic values of a variable $x$, like $x \rightarrow \infty$ (Newman, 2004). Thus, power-laws have played an important role in economics to the extent of warranting an extensive article in the Journal of Economic Perspective (JEP), in which Gabaix (2016) demonstrates their applications in relation to finance, city size, executive salaries and macroeconomics, very different subjects.

While some economic models and hypotheses, such as the efficient market hypothesis of Fama (1970), Malkiel and Fama (1970) and Fama (1991) and the Black 
and Scholes (1973) model have assumed that returns follow a normal distribution, Econophysics has contradicted this since its emergence: if the distribution of stock returns follows a power-law distribution, this implies that large fluctuations in stock exchanges can occur. Accepting that financial markets are subject to wide variations can contribute to mitigation of these financial instabilities or even prevent them (Pereira et al. 2017).

\section{COMPLEX NETWORKS}

At the end of the 1990s, with the discovery of new network topologies such as small world (Watts and Strogatz, 1998) and free of scale (Barabasi and Albert, 1999), the study of complex networks appeared. ${ }^{1}$ Complex systems, in general, involve innumerable elements organized in structures that can exist or coexist, in different scales (Pereira, 2013). Most of their main characteristics emerge from interactions between their constituent parts, and cannot be predicted from an isolated understanding of each of these parts (Costa et al., 2007). In this context, complex networks can be located at the intersection of graph theory and statistical mechanics, involving several knowledge areas, and therefore, their study can be considered as a multidisciplinary approach (Pereira, 2013).

It can also be highlighted that complex networks have contributed to the economy by proposing new methods, techniques and properties (Schweitzer et al. 2009). In this context, one research area which benefited from these new approaches is finance, for which network theory enabled measurement of the probability of systemic risk, due to the interconnections and interdependence between the agents of a given

${ }^{1}$ The structure of a complex network is represented in the same way as a graph in a set $\mathrm{R}$, which, in the case of networks that have no weights in their connections, is defined by $V=$ $\left\{v_{1}, v_{2}, v_{3}, \ldots, v_{n}\right\}$ the nodes (or vertices) and $E=\left\{e_{1}, e_{2}, e_{3}, \ldots, e_{m}\right\}$, the edges or connections that link pairs of nodes. The numbers $n=|V|$ and $m=|E|$ are considered as the quantities of elements in $V$ and $E$ respectively (Newman, 2018). 
system or market, in which the insolvency or bankruptcy of a single entity (or group of entities) can cause chain failures (Jackson 2010, 2014). In this context, Boss et al. (2004) showed that before a financial crisis, the world banks' payment systems were interconnected and had a probability distribution in the form of a power-law, meaning that a large part of the transactions involving those payment systems was concentrated in a very small number of banks, while many others traded a smaller amount.

Economists consider the importance of a payment institution according to the volume of resources it administers. However, the concept of centrality ${ }^{2}$ extracted from complex networks helps to classify the importance of these institutions based on how central they are in a given network (in that case, the financial system). Battiston et al. (2012b, 2016) propose that instead of considering financial institutions "too big to fail" in terms of default risk, they can be considered "too central to fail", i.e. monitoring the centrality of a financial institution rather than its size. This may better explain how a crisis can spread in a banking system, since negative shocks to central financial institutions can cause a system-wide contagion effect. When it is discovered that there are too many central markets to break, this implies that some relevant financial markets such as those of the European Union or the United States have a high centrality and any disturbance in them can affect, practically, the entire network which is connected to them (Pereira et al. 2019).

Complex networks have influenced analysis in finance, as in, for example Haldane and May (2011), who analyzed the banking system as an ecological network susceptible to financial risks due to its topology. Diebold and Yilmaz (2011), using

\footnotetext{
${ }^{2}$ An important property of networks is the centrality, which quantifies the importance of the vertices (or edges) that are in a networked system. In complex networks there is a wide variety of mathematical methods and measures of centrality of vertices that focus on different concepts and definitions of what it is to be central in a network. A simple measure of centrality in a network is the degree of vertex, which represents the number of edges connected to it, being considered one of the most important network metrics (Newman, 2018).
} 
complex networks, demonstrate that during the period preceding the 2008 crisis, markets were more connected and more subject to instability. Highlighted among studies relating complex networks and the contagion effect are Gai and Kapadia (2010), Glasserman and Young (2015) or Acemoglu et al. (2015), who analyse the risk of financial networks and propose that financial contagion shows a form of transition phase, and to a certain extent, strong interconnections serve as a shock propagation mechanism, leading to the fragility of a given network.

\section{COVID CRISIS AS A COMPLEX CRISIS}

The financial system is like an adaptive complex system and the use of networks to analyse it provides a different number of structural vulnerabilities accumulated in the past (Haldane, 2017). The concept of self-organized criticality proposed by Bak et al. (1987) describes a phenomenon appearing in systems that naturally evolve to a critical state without any sensitivity to parameter adjustments or initial configuration arrangements. However, in this critical state, the system is highly susceptible to small changes or noise, which can cause totally unpredictable reactions.

According to Sornette (2003), the greatest falls in stock markets are similar, in the light of statistical physics, to the so-called critical points studied in the transformation phase of solids, liquids and gas. This theory is based on the existence of cooperative behaviour by traders imitating the behaviour of others, leading to a progressive increase in the accumulation of market cooperation or a set of interactions between investors that can be reflected in acceleration of the long-term price for years (Sornette, 2017).

This investor behaviour lasts until just before a crash, when the market enters an unstable phase and any small disturbance or process may have triggered instability. 
Summarising, when financial markets reach a certain stage, they could be subject to crashes, since "noise" can cause a rupture. It is very likely that even before the crash caused by Covid-19, global financial markets like the North American one had entered this stage, given that any shock would cause losses beyond those expected.

Additionally, the financial crisis caused by Covid-19 is different from others, since it does not originate in the financial system, but is caused by a public health problem, as reported by Wagner (2020). It is the first major crisis caused by a pandemic in this century, and the GDP of some countries may fall up to $9.9 \%$ in 2020 (McKibbin and Fernando, 2020). Alone, the S\&P500, the North American stock index fell 30\% between February 20, 2020 and March 21, 2020. However, the increased connection between financial markets (Minoiu et al., 2015) and the increased connection of the global value chain (Cerina et al., 2016) may lead to increased risk due to the high connectivity of the financial system as well as in sectoral interrelationships.

According to Helbing (2013), systemic failures and extreme events are the consequence of highly interconnected systems and the network risks that humans have created. According to this author, the rapid spread of epidemics is the result of global air traffic and can have serious impacts on our global health, social and economic systems, a situation known as hyper-risk. This helps to exemplify how a public health crisis that started in Wuhan, China, in a short time, is affecting many sectors, among them tourism, air transport, commerce, financial markets and finally the public debt of many countries.

\section{CONCLUSION}


Since the global financial crisis, governments around the world have been acting to improve financial stability and reduce the risks of a highly interconnected financial system, using complexity to do so (Yellen, 2013). That said, complexity has been providing methods and models that try to explain the instabilities occurring in different markets, leaving five important lessons for financial markets:

1. Extreme events can occur in stock markets;

2. The financial markets are interconnected;

3. Some sectors or companies are too central to fail;

4. Different systems, for example, public health, transport, industry and finance, are interrelated, increasing the global risk;

5. Financial crises can be complex phenomena, when markets are in a transition phase, when any "shock" can cause a crisis and the consequent contagion effect.

Therefore, the crisis caused by Covid-19 raises risk analysis to another level, requiring the monitoring of several issues lying beyond economic or financial topics, and that risk analysis must incorporate issues related to the environment (for example, increased deforestation in the Amazon or global climate change), public health (spread of this or other epidemics), politics (corruption), credit (more than the usual default analysis, for example, the high university student debt in the USA) and energy (the dependence on oil from regions in geopolitical conflicts), among others. Therefore, there is a need for complexity to understand instability, in particular, high risks due to a globalized, interconnected world with a large volume of information.

\section{References}

Acemoglu, D., Ozdaglar, A., Tahbaz-Salehi, A. 2015 Systemic risk and stability in financial networks. American Economic Review, 105(2), 564-608. 
Arthur, W. B., Durlauf, S. N., Lane, D. A. 1998. Introduction to the economy as an evolving complex system II. Social Systems Research Institute, University of Wisconsin-Madison.

Bak, P., Tang, C., Wiesenfeld, K. 1987. Self-organized criticality: An explanation of the 1/f noise. Physical review letters, 59(4), 381.

Barabási, A. L., Albert, R. 1999. Emergence of scaling in random networks. Science, 286(5439), 509-512.

Battiston, S., Farmer, J. D., Flache, A., Garlaschelli, D., Haldane, A. G., Heesterbeek, H., ... Scheffer, M. (2016). Complexity theory and financial regulation. Science, 351(6275), 818-819.

Battiston, S., Gatti, D. D., Gallegati, M., Greenwald, B., Stiglitz, J. E. 2012a. Liaisons dangereuses: Increasing connectivity, risk sharing, and systemic risk. Journal of economic dynamics and control, 36(8), 1121-1141.

Battiston, S., Puliga, M., Kaushik, R., Tasca, P., Caldarelli, G. 2012b. Debtrank: Too central to fail? financial networks, the fed and systemic risk. Scientific reports, 2, 541.

Black, F., Scholes, M. 1973. The pricing of options and corporate liabilities. Journal of political economy, 81(3), 637-654.

Boss, M., Elsinger, H., Summer, M., Thurner 4, S. 2004. Network topology of the interbank market. Quantitative finance, 4(6), 677-684.

Bouchaud, J. P., Potters, M. 2003. Theory of financial risk and derivative pricing: from statistical physics to risk management. Cambridge University Press.

Cerina, F., Zhu, Z., Chessa, A., Riccaboni, M. 2015. World input-output network. PloS one, 10(7).

Chakrabarti, B. K., Chakraborti, A., Chatterjee, A. 2006. Econophysics and sociophysics: trends and perspectives. John Wiley \& Sons.

Costa, L. D. F., Rodrigues, F. A., Travieso, G., Villas Boas, P. R. 2007. Characterization of complex networks: A survey of measurements. Advances in physics, 56(1), 167-242. 
Diebold, F. X., and Yilmaz, K. 2014. On the network topology of variance decompositions: Measuring the connectedness of financial firms. Journal of Econometrics, 182(1), 119-134.

Dong, E., Du, H., Gardner, L. 2020. An interactive web-based dashboard to track COVID-19 in real time. The Lancet infectious diseases.

Fama, E. 1970. Efficient Capital Markets: A Review of Theory and Empirical Work. The Journal of Finance, 25(2)

Fama, E. 1991. Efficient capital markets: II. The journal of finance, 46(5), 1575-1617.

Farmer, J. D., Foley, D. 2009. The economy needs agent-based modelling. Nature, 460(7256), 685.

Farmer, J. D. Geanakoplos, J. 2009. The virtues and vices of equilibrium and the future of financial economics. Complexity, 14(3), 11-38.

Ferreira, P., Dionísio, A., Zebende, G. F. 2016. Why does the Euro fail? The DCCA approach. Physica A: Statistical Mechanics and its Applications, 443, 543-554.

Gabaix, X. 2009. Power laws in economics and finance. Annu. Rev. Econ., 1(1), 255294.

Gabaix, X. 2016. Power laws in economics: An introduction. Journal of Economic Perspectives, 30(1), 185-206.

Gai, P., Kapadia, S. 2010. Contagion in financial networks. Proceedings of the Royal Society A: Mathematical, Physical and Engineering Sciences, 466(2120), 2401-2423.

Glasserman, P., Young, H. P. 2015. How likely is contagion in financial networks? Journal of Banking \& Finance, 50, 383-399.

Haldane, A. G. 2017. Rethinking financial stability. Peterson Institute for International Economics, October 12th, mimeo.

Haldane, A. G., May, R. M. 2011. Systemic risk in banking ecosystems. Nature, 469(7330), 351-355.

Helbing, D. 2013. Globally networked risks and how to respond. Nature, 497(7447), 51. Henrique, T. 2020. Covid-19 e a Internet (ou Estou em isolamento social físico). Unpublished manuscript dealing with a philosophical reflection on the term physical social isolation. 
Jackson, M. O. 2010. Social and economic networks. Princeton University Press.

Jackson, M. O. 2014. Networks in the understanding of economic behaviors. Journal of Economic Perspectives, 28(4), 3-22.

Kwapień, J., \& Drożdż, S. 2012. Physical approach to complex systems. Physics Reports, 515(3-4), 115-226.

Lux, T. 1996. The stable paretian hypothesis and the frequency of large returns: an examination of major German stocks. Applied Financial Economics 6, 463-475.

Malkiel, B. G., Fama, E. F. 1970. Efficient capital markets: A review of theory and empirical work. The Journal of Finance, 25(2), 383-417.

Mantegna, R. N. 1999. Hierarchical structure in financial markets. The European Physical Journal B-Condensed Matter and Complex Systems, 11(1), 193-197.

Mantegna, R. N., Stanley, H. E. 1999. Introduction to econophysics: correlations and complexity in finance. Cambridge University Press.

McKibbin, W. J., Fernando, R. 2020. The global macroeconomic impacts of COVID19: Seven scenarios.

Minoiu, C., Kang, C., Subrahmanian, V. S., Berea, A. 2015. Does financial connectedness predict crises? Quantitative Finance, 15(4), 607-624.

Newman, M. 2004. Power, laws, pareto distributions and zipf's law. Contemporary Physics 46(5), https://doi.org/10.1080/00107510500052444

Newman, M. 2018. Networks. Oxford University Press.

Pereira, E. J. D. A. L., da Silva, M. F., \& Pereira, H. B. B. 2017. Econophysics: Past and present. Physica A: Statistical Mechanics and its Applications, 473, 251-261.

Pereira, E. J. D. A. L., Ferreira, P. J. S., da Silva, M. F., Miranda, J. G. V., Pereira, H. B. B. 2019. Multiscale network for 20 stock markets using DCCA. Physica A: Statistical Mechanics and its Applications, 529, 121542.

Pereira, H. B. B. 2013. Redes Sociais e Complexas: Aplicações em Difusão do Conhecimento. Academia de Ciências da Bahia: memória, 3, 39-47.

Rosser, J. B. 1999. On the complexities of complex economic dynamics. Journal of Economic Perspectives, 13(4), 169-192. 
Schweitzer, F., Fagiolo, G., Sornette, D., Vega-Redondo, F., Vespignani, A., White, D. R. 2009. Economic networks: The new challenges. Science, 325(5939), 422-425.

Sornette, D. 200). Critical market crashes. Physics Reports, 378(1), 1-98.

Sornette, D. 2017. Why stock markets crash: critical events in complex financial systems. Princeton University Press.

Stanley, H. E., Afanasyev, V., Amaral, L. A. N., Buldyrev, S. V., Goldberger, A. L., Havlin, S., ... \& Prince, P. A. 1996. Anomalous fluctuations in the dynamics of complex systems: from DNA and physiology to econophysics. Physica-Section A, 224(1), 302321.

Wagner, A. F. 2020. What the stock market tells us about the post-COVID-19 world. Nature Human Behaviour. https://doi.org/10.1038/s41562-020-0869-y

Wang, C., Horby, P. W., Hayden, F. G., Gao, G. F. 2020. A novel coronavirus outbreak of global health concern. The Lancet, 395(10223), 470-473.

Watts, D. J., Strogatz, S. H. 1998. Collective dynamics of 'small-world' networks. Nature, 393(6684), 440.

WHO (World Health Organization). 2020. Coronavirus disease 2019 (COVID-19): situation report, 85 .

Yellen, J. 2013. Interconnectedness and Systemic Risk: Lessons from the Financial Crisis and Policy Implications: a speech at the American Economic Association/American Finance Association Joint Luncheon, San Diego, California, January 4, 2013 (No. 631). Board of Governors of the Federal Reserve System (US). 